\title{
A EDUCAÇÃO DAS INFÂNCIAS E O PAPEL DO EDUCADOR ${ }^{1}$
}

\section{CHILDHOODEDUCATION AND THE ROLE OF THE EDUCATOR}

\author{
Eliane Lima Piske \\ Doutoranda em Educ ação Ambiental \\ pelo Programa de Pós-Graduação em Educação Ambiental \\ Universidade Federal de Rio Grande- FURG \\ Rio Grande, RS- Brasil \\ e.nanny@ hotmail.com \\ (i) Narjara Mendes Garcia \\ Doutorado em Educ ação Ambiental \\ Universidade Federal de Rio Grande- FURG \\ Rio Grande, RS- Brasil \\ narjaramg@gmail.com
}

Maria Angela Mattar Yunes Doutora em Educação: Psicologia da Educação. Universidade Salgado de Oliveira- UNIVERSO

Niterói, RJ- Brasil mamyunes@yahoo.com.br

\begin{abstract}
Resumo: O presente artigo, de cunho teórico, tem como objetivo compreender os papéis que os educadores assumem nas instituições educativas formais e não formais em relação às infâncias. A mediação do desenvolvimento humano e suas construções históricas, afetivas e biológic as mobilizam teorias da educação que salientam interfaces de conceitos da biologia do conhecer e da educ ação das infâncias. As reflexões deste texto apresentam o panorama sistêmico dos processos de socialização na educação das crianças, indicando que os contextos podem ser formais, não formais ou informal. Essa demonstração permite concluir que educação é sempre um direito essencial das crianças em qualquer ambiente educativo. Nesses universos, os papéis dos educadores devem estar implicados e guiados pelo ser, fazer e conversar com as crianças.
\end{abstract}

Palavras-chave: Educação. Educadores. Infâncias. Sistêmico.

\begin{abstract}
The main purpose of this theoretic al article is to understand the roles taken by educators in formal and non-formal educational institutions for infancy. The mediation of human development and its historical, affective and biological constructions mobilizes theories of education that highlight interfaces of concepts in biology of knowledge and childhood education. The reflections in this text present the systemic panorama of the processes of socialization in the education of children, indicating that contexts can be formal, non-formal or informal. This demonstration allows us to conclude that education is always an essential right of children in any educational environment. In these scenarios the roles of educators must be involved and guided by being, doing and talking with children.
\end{abstract}

Keywords: Education. Educators. Childhoods. Systemic.

\section{Para citar - (ABNT NBR 6023:2018)}

PISKE, Eliane Lima; GARCIA, Narjara Mendes; YUNES, Maria Ângela Mattar. A educação das infâncias e o papel do educador. Eccos - Revista Cientifica, São Paulo, n. 54, p. 1-18, e13467, jul./set. 2020.

Disponível em: https://doi.org/10.5585/eccos.n54.13467. 


\section{Introdução}

Conhecer e compreender os papéis dos educadores ambientais que trabalham com as infâncias, bem como elucidar as suas implicações nas formas de ser, fazer, estar e transitar na educação, é tema de relevância inquestionável no mundo contemporâneo. Nesse artigo, a educação das infâncias e suas construções históricas, afetivas e biológicas serão consideradas a partir de três influências: a cultura, a linguagem e a educação guiadas pelos fundamentos teóricos da Biologia do Conhecer. Essa dimensão da biologia apresenta o que são as bases biológicas da compreensão humana, já que, conforme Maturana e Varela (2011, p. 33): "não há descontinuidade entre o social, o humano e suas raízes biológicas. O fenômeno do conhecer é um todo integrado e está fundamentado da mesma forma em todos os seus âmbitos".

Apresentar um levantamento teórico não tem como intenção encerrar uma discussão em termos de compreensão da Biologia do Conhecer (MATURANA; VARELA, 2011) e da educação das infâncias. Ambas são complexas e mobilizam atrelar ciências que rompem com a dicotomia entre conhecer e viver as culturas das infâncias na educação (PINTO; SARMENTO, 1997; SARMENTO, 2003, DELGADO, 2003), as interações de pares (CORSARO, 2011) e a busca das identidades profissionais (GOMES, 2013). Sendo assim, almejamos identificar os papéis que assumem os educadores das infâncias em instituições educativas formais e não formais, além de discutir conceitos que nos ajudam a entender a experiência de viver e conhecer a educação das infâncias. Isso é o que nos move e o que está nos unindo na conversação/reflexão: a educação das/nas (com as) infâncias na transição histórica, ancorada em diferentes autores (COHN, 2009; DELGADO, 2011).

De acordo com Pinto e Sarmento (1997), o papel dos profissionais de educação é de interlocutores fundamentais nas reflexões e decisões de política educativa. Isso coaduna com a ótica argumentativa de que tanto os profissionais de educação (estudantes de licenciatura, monitores, educadores sociais, professores, recreacionistas e etc.) como as figuras parentais e quaisquer outros cuidadores, sejam pais biológicos, adotivos, sociais e/ou avós, são: “adultos educadores" (expressão usada por VIANA, et al., 2017, p. 50, grifo nosso). Sendo assim, Piske, Yunes e Garcia (2019) destacam que os profissionais de educação e as figuras parentais são considerados os educadores ambientais das infâncias, o que está em conformidade com a educação como um direito humano (BAZÍLIO; KRAMER, 2011).

Educação pode se dar em qualquer contexto que se pretenda praticar educação. Apenas o ambiente é que vai diferenciar se é um espaço formal ou não formal. Esmiuçar uma teoria na intenção de mobilizar pensamentos e práticas sobre a educação das infâncias não é e nem 
poderia ser uma tarefa fácil, ainda mais se tratando de uma busca das identidades profissionais. Gomes (2013) aponta para a importância de pensarmos questões afetivas, contextuais e aquelas relativas ao apoio de processos reflexivos e de mudanças de paradigmas na ou para a educação de crianças pequenas.

O atravessamento educativo teórico que os autores Maturana e Varela (2011) pressupõem é uma possibilidade de conversa(ação) desses conceitos: papéis, infâncias, amorosidade e educação. Estes saberes não são imperativos, mas compõe a identidade que sustenta o olhar bioecológico, os símbolos, os discursos, os recortes dos que se constituem como educadores das infâncias. Conversar com a linguagem e com as emoções são sustentáculos dos educadores ambientais das infâncias. De acordo com Maturana e Verden-Zöller (2011,p. 261), as conversações são "resultado do entrelaçamento do linguajear e do emocionar, no qual acontecem todas as atividades humanas. Existimos no conversar, e tudo o que fazemos como seres humanos se dá em conversas e redes de conversações".

Maturana e Varela (2011) trazem ainda as possibilidades de aliar e discorrer sobre as questões ambientais: pela origem do mundo, do conhecer, da natureza e da vida, sendo estas as bases biológicas da compreensão humana. Esses autores defendem os conhecimentos no contexto biológico pela preservação natural e pelas questões dos ambientes em sua totalidade. Afirmam Maturana e Varela (2011, p, 195): "falamos em conhecimento toda vez que observamos um comportamento efetivo (ou adequado) num contexto assinalado. Ou seja, num domínio que definimos com uma pergunta (explicita ou implícita) que formulamos como observadores".

O que nos permitiu "maturar"" um alinhavo sistêmico (CAPRA, 2006; CAPRA; LUISI, 2014; PISKE, YUNES e GARCIA, 2019) são os espaços de relações que fazem, constroem os papéis e ajudam a entender a experiência do educar e do conhecer as infâncias. Corroborando com as expressões de Oliveira-Formosinho (1998b), o desenvolvimento profissional de educadores das infâncias, em sua complexidade, pode explanar a diversidade em ser, estar e conhecer pelas características que são marcantes na educação das crianças.

Importante ressaltar que a intenção aqui posta é de compreender os papéis dos educadores pela e com a educação das infâncias (MATURANA e VERDEN-ZÖLLER, 2011, MATURANA, 1998; STONE, et al., 2006; BAZÍLIO e KRAMER, 2011; FILHO e CASTRO, 2018). Maturana e Varela (2011) exemplificam a teoria com exemplos práticos sobre os quais podemos refletir acerca da nossa corresponsabilidade. Releva-se que nós, adultos, não deveríamos nos preocupar somente com o futuro das crianças, mas precisamos atentar ao que somos, ao que fazemos e como compartilhamos conhecimentos nas múltiplas instituições 
educativas. Ao chegarem à vida adulta, as crianças exercerão o que aprenderam nas redes de conversação, conforme podemos observar na fala de Maturana e Varela (2011, p. 31): "não temos outra alternativa, pois há uma inseparabilidade entre o que fazemos e nossa experiência no mundo, com suas regularidades: seus lugares públicos, suas crianças e guerras atômicas". A educação é o que fazemos agora! As crianças não são o futuro, pois, vivem e são o agora, o hoje, o presente!

É preciso estabelecer uma relação de respeito, de aceitação, de tranquilidade, de liberdade e de amorosidade com as crianças. Com isso, não quer dizer que não se permita dizer "não" às crianças, para que elas possam (re)pensar suas atuações, pensamentos e comportamentos, mas devemos conversar com elas e estar sempre nos cuidando para não tropeçar, sempre com uma postura vigilante, já que nossos atos têm um papel decisivo sobre os sentimentos e as ações das crianças. Maturana exemplifica:

O que fazer? Não castiguemos nos sas crianças por serem, ao corrigir suas ações. Não
des valorizemos nossas crianças em função daquilo que não sabem; valorizemos seu
saber. Guiemos nos sas crianças na direção de um fazer (saber) que tenha relação com
seu mundo cotidiano. Convidemos nossas crianças a olhar o que fazem e, sobretudo,
não as levemos a competir (MATURANA, 1998, p. 35).

Na vida adulta as crianças poderão espalhar o que vivenciaram. Muitas vezes, os adultos falam uma coisa para as crianças e fazem outra, esquecendo que as crianças estão observando suas atitudes. A criança começa a perceber que existe um modo de viver adulto, em que os adultos são, muitas vezes, dispersos e desconsideram que as crianças são movidas por pormenores de suas ações e intenções. As crianças observam os detalhes e ficam atentas às situações entre os adultos. Podem, portanto, começar a perceber que aquele é o modo correto de se viver na vida adulta, de acordo com o que dizem Filho e Castro (2018, p. 13): "nesse ínterim se define fundamentalmente o papel de professores(as) e profissionais que atuam diretamente com as crianças e se instrumentalizam na realização de propostas de continuidade das experiências para crianças e adultos".

Como os educadores das infâncias vão educar, o que querem explicar e o que vão mobilizar é papel que cada um precisa assumir com o coletivo do quefazer no mundo e com o mundo, conforme Maturana e Verden-Zöller (2011, p. 110): “assim, a vida que vivemos, o que somos e o que chegaremos a ser- e também o mundo ou os mundos que construímos com o viver e o modo como os vivemos - são sempre o nosso fazer". A responsabilidade é exclusiva de cada um de nós e o outro não é o responsável pelo que pensamos, fazemos ou dizemos. Entra em cena a corresponsabilidade como um elemento da educação das infâncias. A ideia da corresponsabilidade é aliada na cooperação, na conversação, na liberdade, na democracia, na 
participação, na reflexão e na solidariedade, que, com outros valores, consolidam a educação das infâncias (BARCELOS; MADERS, 2018).

Para intervir é necessário mobilizar. Com isso, não se quer afirmar que vamos mudar o mundo/sistema com a educação das infâncias pelas bases da solidariedade, respeito, escuta, cooperação, interação, ética, emoção, amorosidade e democracia. Todavia, conversar pode fazer com que a criança reflita e tenha oportunidade de mudar seus atos, através da educação. De acordo com Veca, et al.,(2013, p. 19): “um ambiente com bem-estar global é um ecossistema diversificado, estimulante e acolhedor, no qual cada habitante faz parte de um grupo ao mesmo tempo em que tem espaços de privacidade para que possa obter uma pausa dos ritmos gerais". Sendo assim, trabalhar o local para atingir o global é a proposta da educação das infâncias também na perspectiva de Maturana:

A educação é um processo contínuo que dura toda a vida, e que faz da comunidade
onde vivemos um mundo espontaneamente conservador, ao qual o educar se refere.
Is so não significa, é claro, que o mundo do educar não mude, mas sim que a educação,
como sistema de formação da criança e do adulto, tem efeitos de longa duração que
não mudam facilmente (MATURANA, 1998, p. 29).

Estamos avante na ideia das percepções do mundo, da educação e dos papéis dos educadores das infâncias, pois constatamos que para intervir e legitimarmos as crianças ao conversar com elas está em conformidade com a educação das infâncias. Mas, surge o questionamento sensibilizado por Bazílio e Kramer (2011, p. 107): "que papel tem os diferentes espaços de produção cultural? Que mundo ensinam as crianças? Podem esses espaços ser diferentes?". Falar sobre papéis sob o prisma de atividades que são as práticas, as teorias e os contextos educativos, que passamos a operar com o outro, pode ser motivador. Os papéis que assumem os educadores das infâncias são formados nas práticas relacionais, ambientais e interpessoais de uma conversa(ação), que é sistêmica (PISKE, YUNES e GARCIA, 2019). O educador está implicado nas práticas educativas e, se for observador, refletirá sobre suas ações. Isso pouco difere das relações familiares que acontecem em espaços não formais, e defendemos que os pais são importantes educadores das infâncias. Da mesma forma, se for observador e se perguntar será um educador que opera.

O operar, para Maturana e Varela (2011), é o fazer, que é uma relação da ação, no sentido de relacionar as coisas e os indivíduos no mundo e com o mundo para conviver. O que vem ao encontro da expressão de Maturana e Verden-Zöller (2011, p. 198): “ocorre mediante o viver em coexistência humana da criança com os seus pais, em total e mútua aceitação corporal. Quando esse desenvolvimento acontece de modo adequado, torna-se um ser humano socialmente bem integrado é um processo natural". Que educadores queremos para pensar as 
educações das infâncias? Se observássemos com mais atenção as infâncias, superaríamos barreiras e proporcionaríamos um salto grande na educação. Mas nós olhamos para as crianças? Conversamos com elas? Que afinidades se estabelecem entre as figuras parentais e os profissionais de educação? Que relações são estas? Já mencionamos que operamos com o conceito de educadores das infâncias, tanto nas figuras parentais como nos profissionais de educação. Vamos começar pensando nas famílias. Desde pequenas, as crianças começam a observar que os pais tentam impor os limites corporais que elas podem e/ou não realizar, conforme podemos decifrar com o fragmento a seguir:

\begin{abstract}
Alguns meses depois de aprender a andar, minha filha gostava de praticar sua nova mobilidade escalando lugares que, para mim e minha esposa, pareciam muito perigosos. Com frequência, a tirávamos do alto de poltronas e de outros móveis, colocando-a de volta ao chão, e a advertindo sobre os perigos de tal comportamento. Depois de diversas repetições desses episódios, a ouvi me chamar um dia e, quando me voltei a olhar, ela estava em pé, no alto do encosto de uma grande poltrona. Eu respirei fundo e corri para tirá-la de lá, e fui obrigado a rir do enorme sorriso de alegria que ela trazia em seu rosto. Ela estava claramente comunicando: "Eu papai, olha o que eu fiz dessa vez!" (CORSARO, 2011, p. 100).
\end{abstract}

Como as crianças lidam com essas situações? Não podemos esquecer que as crianças são atores sociais que estão sendo evidentes às alterações ao longo das épocas, acerca das infâncias, conforme Carvalho, Pedrosa e Rossetti-Ferreira (2012, p. 91): "pensar sobre o bebê hoje é diferente de como se pensava 50 ou 60 anos atrás. Na última metade do século XX, ocorreram transformações rápidas e surpreendentes nessas concepções (...)”. As pesquisas começaram a investigar as possibilidades das instituições educativas nas infâncias das/para/com as crianças, como relata Delgado (2011, p. 185, grifo nosso): "há registros de estudos das ciências sociais sobre a infância desde 1930, mas estes se desenvolviam de forma esparsa". Depois foram para, como Cohn (2009) menciona que a própria Antropologia da criança começou a alterar a visão sobre as infâncias, sendo que as pesquisas começaram a ser realizadas das crianças, depois perceberam que teriam que fazer para elas e, por fim, com as crianças. Sendo assim, Cohn (2013, p. 221) aponta ser necessário "uma leitura da produção em antropologia que foca suas pesquisas nas crianças, sejam pesquisas sobre ou com crianças”.

Neste ínterim, é a questão da mudança da antiguidade para a modernidade, que dá, por fim, uma visão pós-moderna das infâncias. Conforme podemos visualizar com o quadro a seguir: 
Quadro 1 - Imagens sociais das crianças ao longo da época

\begin{tabular}{c|c}
\hline Época & Crianças \\
\hline Antiguidade & Mini-adulto \\
\hline Modernidade & Preocupação social \\
\hline Contemporaneidade & Categoria social \\
\hline
\end{tabular}

Fonte: PISKE, et al., 2016.

Segundo Piske et al. (2016, p. 565) :“a história não é linear e estas concepções coexistem no imaginário social, o que nos possibilita compreender que os atravessamentos das crianças tiveram três momentos históricos: antiguidade, modernidade e contemporaneidade". O que vamos falar de infâncias se refere a conhecer historicamente, explicar biologicamente e observar culturalmente. Trata-se de tudo numa ação do que é e faz parte das crianças para e com o viver no mundo, sendo, portanto, uma tríade intrínseca a educação das/nas/com as infầncias. Maturana (1998, p. 37) evidencia que: "as reflexões epistemológicas surgem com a pergunta: Como é que conhecemos? Esta pergunta pode ser proposta sem que nos comprometamos verdadeiramente a aceitar que o fenômeno do conhecer é um fenômeno biológico". A ação é aquilo que move a teoria, que dá a ideia do que podemos contribuir e, por ser verbo, nos processos é o próprio operar. No alcance desse nível, ocorrem as interações afetivas: o viver ao fazer, que é a ação do educar, pois segundo Maturana (1998, p. 29): “o educar ocorre, portanto, todo o tempo e de maneira recíproca".

Educar é algo que fazemos no nosso conviver. Então, o que é educar para os educadores das infâncias? É a influência do contexto como um todo, desde o microssistema ao macrossistema, no sentido dos valores, da representação social que se tem sobre aquela função, que é o educar, em que as palavras surgem e são verbos. A ação é a peça chave, pois a ação é o conhecer e o conhecer é a ação! Maturana e Varela (2011, p.32) exemplificam que: "todo fazer é um conhecer e todo conhecer é um fazer". A aceitação é o fazer, então operar a teoria é justamente essa a ideia: de relação, de ação, no sentido de relacionar as coisas pelo respeito, como reitera Maturana (1998, p. 31): "sem aceitação e respeito por si não se pode aceitar e respeitar o outro, e sem aceitar o outro como legítimo outro na convivência, não há fenômeno social". O educar é algo que fazemos no e com o viver. Percebemos isso nas palavras de Maturana e Yañez (2009, p. 185): "vivemos tudo o que vivemos como válido no momento de vivê-lo e, nesse viver, tratamos como válidas as coerências operacionais que surgem como constituindo o espaço relacional que emerge com nosso viver" 
Ser ao conhecer e estar em permanente movimento são o que movem nossa existência, afirma Maturana (1998, p. 37): “o fenômeno do conhecer é um fenômeno biológico”. O modelo de sociedade a que pertencemos foi constituído por nós, seres humanos, conforme mencionam Carvalho, Pedrosa e Rossetti-Ferreira (2012, p. 91): "cada sociedade humana, a mesma sociedade em diferentes momentos de sua história, e diferentes grupos dentro da mesma sociedade têm suas próprias concepções sobre o que é um bebê, uma criança, um ser humano". Nenhum outro ser vivo tem essa capacidade, esse conjunto de circunstancialidade que se desenha num tempo e se constitui na memória e na complexidade dos sistemas (CAPRA, 2006; PISKE, GARCIA e YUNES, 2019). A conjectura sistêmica é latente, já que é uma engrenagem de múltiplos elos, que precisam estar e permanecer em sintonia para que os funcionamentos das peças movimentem o todo. Sendo assim, a máquina precisa dos componentes para seu funcionamento e é necessário conhecer esses mecanismos para que elas trabalhem. Nós, seres vivos, também necessitamos de uma organização:

\footnotetext{
O fato de que o conhecer seja o fazer daquele que conhece está enraizado na própria maneira de seu ser vivo, em sua organização. Sustentamos que as bases biológicas do conhecer não podem ser entendidas somente por meio do exame do sistema nervoso. Parece-nos necessário compreender como esses processos se enraízam na totalidade do ser vivo (MATURANA e VARELA, 2011, p. 40).
}

Temos que compreender a organização dos seres vivos em sua totalidade: inteligência, cérebro, coração e emoção, na lógica social e no contexto concreto em que são experienciados. Não podemos esquecer que os papéis têm influências nas questões culturais e nos contextos sociais, pois são as bases biológicas do conhecer (MATURANA e VARELA, 2011). Somos nós que apresentamos identidade para o lugar no momento que (re)significamos este para a nossa constituição, enquanto sujeitos pertencentes a um contexto sócio-biológico-sistêmico que é formado pela cultura, a biologia e a complexidade do tempo: tríade interativa. Perante Gomes (2013, p. 31): “em nossa opinião, grande desafio que se apresenta hoje à sociedade, em geral, e à educação, em particular, é o equilibbrio das relações entre o coletivo e o individual, o público e o privado, o pensamento flexível e o pensamento único/homogêneo"

Não podemos esquecer que os seres vivos estão interligados no e com o mundo, por isso é importante uma conversação entre os condicionantes, consoante Maturana e Varela (2011, p. 67): "cada vez que, num sistema, um estado surge como modificação de um estado prévio, temos um fenômeno histórico". É necessário sermos um compartilhar cultural, afetivo e social do meio ao qual pertencemos, construímos e que podemos modificar pelas ações que precisam e devem ser em sua totalidade de atuações. 
A visão sistêmica do mundo pelo ser educador das infâncias possibilita encontrar a sintonia para que humanos e suas relações sejam mais afetuosas. As pessoas não são e/ou estão isoladas do contexto, mas, sim, precisamos entender que tudo está relacionado, que não temos como tirar a pessoa do lugar, pois ele é o ambiente, uma forma de sistemas. Então, o que é a perspectiva sistêmica? A visão sistêmica é uma forma de olhar e atuar no mundo e com ele, percebendo, assim, as conexões entre e com as pessoas e o ambiente (PISKE, YUNES e GARCIA, 2019; CAPRA, 2006). Os sistemas são níveis de entendimento, extensões em que podemos dimensionar pelo ser, e não pelo ter, sendo fundante aos papéis dos educadores das infâncias pelo tempo e processo com as educações que estão implicadas pelas abordagens sistêmicas nos múltiplos contextos.

\section{Os papéis dos educadores das infâncias}

Para escrever sobre os papéis dos educadores em diferentes ambientes é necessário conhecer as peculiaridades dos contextos ecológicos, sobretudo, não esquecendo que esses lugares guardam memórias e marcas de uma sociedade que pertence ao seu meio biológico. Não existe experiência que não seja "em" contexto. O papel que ocupamos em um determinado contexto influencia a forma como vamos nos comportar/comprometer no ambiente. Maturana e Varela (2011) falam dos domínios de ação em que cada um, dos quais atuamos, vai predizer um papel. A forma como agimos está suportada numa emoção e fundada no papel desempenhado pelos próprios processos que são fundamentados na linguagem. Sendo assim, os papéis são as ações assumidas, como Maturana e Varela (2011, p. 270-271) explicam que: "contribuem para formar o mundo em que existimos e que validamos por meio deles, num processo que configura o nosso porvir. (...) O papel que representamos, com o ser que verdadeiramente construímos no nosso viver cotidiano".

Percebemos a importância dos processos que são fundamentados na linguagem do conhecer, sendo que o papel da interação influencia na forma como vamos nos relacionar com as pessoas e o meio, o que queremos fazer e como vamos nos comprometer. Os papéis assumidos determinam e são consequências das nossas ações/escolhas no nosso fazer, conforme:

\footnotetext{
Afirmamos que, no âmago das dificuldades do homem atual, está seu desconhecimento do conhecer. Não é o conhecimento, mas sim o conhecimento que cria o comprometimento. Não é saber que a bomba mata, e sim saber o que queremos fazer com ela que determina se faremos explodir ou não (MATURANA; VARELA, 2011, p. 270).
} 
Para a Biologia do Conhecer, também conhecida como "autopoiese", nós somos sistemas fechados; somos seres "autopoéticos", palavra cunhada por Maturana e Varela (2011). A "autopoiese" é a capacidade que os seres vivos têm de se autoproduzir, conforme afirmam Maturana e Varela (2011, p. 55): “o que caracteriza o ser vivo é sua organização. Seres vivos diferentes se distinguem porque têm estruturas distintas, mas são iguais em organização". Vale mencionar que, para a Biologia do Conhecer, são seres vivos independentemente de serem humanos ou não. Todo o ser vivo é capaz da autoprodução. Mencionando esse termo: autoprodução, lembramos que o equilibrio de poder percorre a reciprocidade, que está interligada na relação de autoprodução, sendo eixos interativos: o equilibrio de poder, a autopoiese, a reciprocidade e as relações afetivas, em que se complementam com a pessoa e o contexto. De acordo com a Biologia do Conhecer, sempre seremos sistemas fechados, o que significa o rompimento de dualidades: biologia e cultura, mente e corpo, pessoa e natureza, pois não faremos distinções: somos sistemas fechados, conforme apresentam Maturana e Varela (2011, p. 114): “a contínua mudança estrutural dos seres vivos com conservação de sua autopoiese acontece a cada instante, incessantemente e de muitas maneiras simultâneas. É o palpitar da vida". O sistema é fechado, mas é só ter uma interação que ele se modifica. Nós nos alteramos pela interação com o meio e com as pessoas. No processo autopoiese, a interação com o outro e com o meio são elementos que fazem parte das ações e arranjos, a partir de outras organizações já realizadas.

A pessoa é uma interação consigo mesma e com o outro. É a auto-organização que vai se constituindo e tem a interação com o outro, recursivamente. Nós vamos mudando em relação ao que vamos conhecendo, por isso a congruência. A teoria é um ciclo: vai e vem. Maturana (1998) explica que a responsabilidade é toda do sujeito, ela não depende do outro, embora possa gerar perturbações. Com a intenção de mostrar que os seres vivos são sistemas fechados, Maturana (1998, p. 61) apresenta desenhos, seguidos da explicação: "no qual se conserva a congruência entre o ser vivo e o meio, e na qual, por conseguinte, o meio muda junto com o organismo que nele está". A totalidade bioecológica é dinâmica e denominada unidade ecológica organismo-nicho.

Com essa elucidação, Maturana (1998) mostra que existe uma interação: as duas cavidades representam a pessoa e embaixo é o ambiente. As duas cavidades apresentam que há uma influência mútua, que são recíprocas. O autor faz várias setas, de um para o outro, entre o ambiente e no próprio sistema, como um sistema fechado, estruturalmente, e quando se rompe é a morte, representado pela cruz. Podemos perceber a capacidade que temos da autoprodução, tudo que acontece conosco é gerado/organizado por nós mesmos. É neste sentido que ele coloca 
uma seta maior: a estrutura. É uma pessoa só, a representação é a interação do indivíduo transformado por ele mesmo com o meio, que se altera. É a mesma pessoa, um único ser que vai se transformando ao longo do tempo.

Podemos acompanhar com a explicação, primeiramente representado por uma bola redonda e depois uma bola mais achatada, que simula essa transformação. Quando o sujeito não consegue essa congruência entre o sujeito e o meio, é a morte, representada por uma cruz ao lado da imagem (MATURANA, 1998). As setas menores não representam a interação, mas a transformação da pessoa, a alteração da primeira bola pela segunda, mais achatada, não é mais tão redonda. Como sistemas vivos nós somos permeáveis, não vamos deixar de ser sistema fechado. Mas, sim, a nossa estrutura que é a própria organização.

Agora, pensamos a partir da representação imaginativa de outra imagem, em que Maturana (1998) considera a pessoa A e a pessoa B. No contorno que representa a interação entre os dois sujeitos, podemos imaginar como acontece a congruência, tendo relação com os acoplamentos estruturais. Com a explicação observamos que a pessoa está em interação com a outra e ambas se transformam. O acoplamento estrutural é quando conseguimos ligar alguma coisa a nossa estrutura e elas dão sentido, na definição da autoprodução. Também existe o acoplamento do contrário, quando há a rejeição. A seguir, iremos entender a explicação pelas próprias palavras do autor:

\begin{abstract}
A consequência dis so tudo é que somos como somos em congruência com nosso meio e que nosso meio é como é em congruência conosco, e quando esta congruência se perde, não somos mais. Essa dinâmica constitutiva recíproca é válida para um organismo, qualquer que seja o seu meio e, no nosso caso, os seres humanos, qualquer que seja nossa dinâmica de convivência. Se dois seres vivos se encontram em interações recorrentes, como na Figura, há uma história de mudança estrutural congruente entre eles, na qual o meio de $\mathrm{A}$ inclui $\mathrm{B}$ e $\mathrm{C}$, o de $\mathrm{B}$ inclui $\mathrm{A}$ e $\mathrm{C}$, e o de $\mathrm{C}$ inclui A e B. Esta mudança congruente acontece de qualquer jeito, independente de nossa vontade, e todos sabemos disso (MATURANA, 1998, p. 63).
\end{abstract}

Com a elucidação, Maturana (1998) apresenta as congruências acompanhadas pelas duas bolas que se encaixam, como se fosse um quebra-cabeça, ou seja, a pessoa A está abstrusa e a pessoa B está curvada, ou ao contrário, o que importa é que elas estão se encaixando.Há uma congruência na transformação dessa interação, não é só uma pessoa que se transforma a outra também, assim como o meio que se modifica. É essa transformação que é gerada por essa interação com o meio.

$\mathrm{O}$ que demanda a autoprodução é a capacidade da pessoa, do ser vivo interagir. $\mathrm{Na}$ Biologia do Conhecer, se torna impossível dizer que o corpo não faz parte da mente para se autoproduzir (MATURANA; VARELA, 2011). A organização é o funcionamento, então, é o 
movimento do ser vivo é o processo dele que não muda, mesmo que nossa estrutura mude, vamos continuar sendo seres vivos, só não conseguimos manter essa organização na morte.

As elucidações contemplam a pessoa e o desenvolvimento humano no contexto. Nós, através dos tempos, fomos de certa forma tentando separar a cultura da biologia, ou ainda, das questões ambientais, embora cientes que não podemos separar esses elementos (MATURANA, 1998; MATURANA; VERDEN-ZOLLER, 2011; PISKE e GARCIA E YUNES, 2019).Com as dimensões citadas, percebemos que não podemos continuar fazendo essas confusões/dicotomias entre a pessoa e o ambiente, a cultura e a biologia, como se fosse possível sermos fora do mundo natural, como se não fossemos a natureza/ambiente:

\begin{abstract}
O mundo natural só existe quando o vivemos nessa condição, ao vivermos como seres humanos. Um bosque só é umbosque se ao vê-lo não o cortamos. Um lago só é natural e cheio de vida e beleza se, ao vê-lo, não o contaminarmos... Além do mais, só existiremos se ao distinguir-nos como seres humanos conservarmos o mundo natural que surge conosco, no ato de nossa própria distinção. Como fazer is so? Ampliando o conhecimento e a consciência em relação à interlig ação dos processos dabiosfera, e também sobre a capacidade humana de agir como parte dela (MATURANA; VERDEN-ZÖLLER, 2011, p. 260).
\end{abstract}

Maturana e Varela (2011) falam da questão social, do ambiente e do olhar biológico: de perceber o outro como legítimo outro. O olhar social, a aceitação do outro e a legitimação são fatores biológicos. A forma como está desenhada a imagem e pela explicação representa uma coisa única, sem linhas para separar, o que também é acompanhada pela autoprodução. O sistema fechado não vive mais sozinho, vive em interação com o meio (MATURANA, 1998). Os sistemas fechados possibilitam entender o ser humano sem estar e sem ser dissociada das questões biológicas e culturais, importante percepção para compreender a pessoa, o contexto e a educação. A educação é sempre um direito essencial das infâncias em qualquer ambiente educativo. Então numa relação que temos na comunidade, também teremos educação, pois somos educadores e os contextos também educam. A questão a ser problematizada é: quais os papéis que devem ser assumidos pelos educadores ambientais das infâncias nos múltiplos contextos?

Precisamos (re)pensar o binarismo que se cria entre a natureza e o homem. Existe sociedade sem natureza? Existe natureza sem sociedade? Nós é que criamos essas divisões. Quando falamos das relações, estamos falando das afinidades nos diferentes contextos, talvez o que tenhamos que pensar e reforçar é que os educadores das infâncias, as crianças e os anima is não estão flutuando, mas fazem e agregam no mundo e com o mundo, compreendendo que fazem parte de um município, que tem uma política social que está implementada, isto é, todos estão num bairro, numa rua, numa casa e a natureza está ali, não está apenas na forma da árvore, 
por exemplo, a natureza está construída se forma dentro desse contexto. Quando precisamos destacar que a natureza é a areia e/ou a árvore é por que estamos fazendo binarismos, criando secções.

A natureza não está seccionada das questões sociais, tanto que é necessário o cuidado com o ambiente, pela ética que é dever e pelo próprio zelo, o que converge com as esferas de valores pela vida, que é a educação, conforme relata Maturana (1998, p. 29): "a educação como "sistema educacional" configura um mundo, e os educandos confirmam em seu viver o mundo que viveram em sua educação. Os educadores, por sua vez, confirmam o mundo que viveram ao ser educados no educar". Estamos falando de natureza quando mencionamos as interações humanas que são e fazem parte da educação. O ser humano é um sujeito social e natural, ele é biológico de acordo com Maturana e Verden-Zöller (2011, p. 33): “(...) nenhuma ação e emoção particulares definem uma cultura, porque esta, como rede de conversações, é uma configuração de coordenações de ações e emoções". A educação vai ser sempre intencional e organizada. Nesse sentido, vale ressaltar os questionamentos de Viana et al., (2017, p. 69-70): "mas a educação só existe no interior de uma escola? Existe vida além desse espaço? Pensamos que sim, pois o aprendizado é um processo contínuo e inacabado e que espaços, situações e outras pessoas podem nos ensinar e ampliar nossa maneira de ver/sentir o mundo".

Podemos dizer que existem ambientes não formais, todavia a educação também ocorre nesses contextos. Os professores têm um planejamento, as figuras parentais também têm, mesmo que não seja explícito e/ou não esteja documentado e registrado, os familiares também planejam e organizam os momentos pensando nas crianças. Muitas vezes, pode não ser a melhor forma de arranjo, mas existe. A própria rotina é uma forma de organização, citamos um exemplo: quando a criança acordar irá para a escola. O planejamento familiar são os combinados que se estabelecem entre o(s) adulto(s) e a(s) criança(s). As imposições em ordenar e as preocupações em impor limites, sem conversar com a(s) criança(s) que precisam ser (re)pensadas: quando escutamos os pais mencionarem que não aguentam mais ver o(s) filho(s) com o celular, por exemplo, perguntamos: mas, quem ofereceu o celular para a(s) criança(s)? Quais foram os combinados? Destacamos as palavras de Maturana e Verden-Zöller (2011, p. 198-199): "fazemos isso quando mergulhamos em preocupações com o futuro e o passado e assim nos desencontramos dos outros - em especial de nossos filhos -, por não vê-los precisamente porque nossa atenção está em outra parte".

A educação não formal se caracteriza por permitir novas alternativas de educação não oficializadas. O que não podemos e não devemos fazer é separar a educação, mas sim definir como maneiras de ensinar/aprender em diferentes contextos, que podem ser formais, informais 
ou não formais. Contudo, a educação permeia todos esses ambientes, de acordo com Viana et al., (2017, p. 71): "então, independente se for formal, informal ou não formal, a educação é nosso bem maior, nosso patrimônio social, histórico e cultural". A educação informal sempre existiu, até se formarem as instituições, o qual tornando-se formalizado esse processo, o ensino formal surge a partir da informalidade. Porém, não significa dizer que não existe educação informal na escola, por exemplo, e/ou que não existe educação formal nas famílias, só não é estabelecido como currículo, que é trabalhado na escola como formal. Precisamos ultrapassar a ideia de classificar a educação, o necessário é considerar os espaços que ocorrem o educar: se são ambientes formais, informais ou não formais.

As escolas têm papéis determinados e as famílias têm outros, mas à medida que a própria escola trata a família como não formal, desvaloriza os papéis que elas têm. A ideia do não formal é como se fosse uma coisa aquém, menos importante, com pouco valor. A educação não pode usar os recursos que vem apenas do âmbito formal, todavia destaca Brandão $(2003$, p. 8): “com uma ou várias: educação? Educações[!]”. Sendo assim, não podemos separar a educação ou dividi-la, pois educação é um aprendizado que se constitui a partir de diferentes elementos, que acontece em diversos ambientes (educação), ou melhor, podemos considerar o termo educações, partindo do pressuposto de que são diferentes e diversos os contextos que abarcam esse processo!

A educação ocorre e está presente nos múltiplos contextos, nos artefatos culturais, nas relações familiares e escolares, nas comunidades e, tudo isso é educação. O que vai diferenciar é o ambiente, onde ocorre, se o espaço é formal, informal ou não formal, sendo que o lugar que vai trazer elementos, mas, são educações, salienta Goméz (2017, p. 74): “é preciso romper com esse monopólio e crença generalizada de que educação só tem a ver com o escolar. Esse seria o caso dos meios de comunicação de massa e, hoje, das diversas tecnologias e das redes sociais que, sem reconhecer-se educadores estão educando". Temos que desmistificar que não temos educação em espaços não formais, o que contribuiu sobremaneira para identificar e reconhecer os educadores, pois se não podemos separar educação por espaços também não podemos dizer que apenas professores são os educadores das infâncias.

\section{A educação é o que fazemos no aqui e agora!}

Como já mencionado, trabalhamos com o conceito de educadores das infâncias: as figuras parentais e os profissionais da educação, que são educadores em múltiplos contextos educativos. Para construir formas diferentes de ser educador Das/nas/ (com as) infâncias, não 
se pode deixar para amanhã, mas, sim, e juntos podemos e devemos fazer hoje! A felicidade de conviver com as infâncias deve ser expressa no aqui e agora.

Ressaltamos que o que foi apresentado nesse artigo sobre a educação teve como base a teoria da conversa(ação), da emoção, das bases de estar com o outro e das relações de interação, que são sistemas epistemológicos de cuidado/dever com a ética/vida que fazem conexões com o quefazer e não com o que deveríamos fazer. Estas são as preposições sistêmicas da educação das infâncias. Reconhecer os papéis dos educadores como mediadores do aqui e do agora e tendo as infâncias como protagonistas na educação, o que implica em conhecer o ambiente, deixar que a emoção circule e permeie as práticas educativas ambientais.

Estar junto com as crianças e construir práticas educativas ambientais devem envolver: a conversa, a gentileza, o respeito, a emoção, a alteridade, a paciência, a liberdade e muito mais! É a conversa(ação) do aqui e do agora com as infâncias! A educação é o que fazemos no presente, sendo que as práticas educativas devem coordenar e cooperar com as ações que são ambientais. É relevante que os discursos de conversa(ação) pela educação devem ser assumidos nos diferentes contextos microssistêmicos ecológicos e que as atuações devem ser e estar nas práticas cotidianas Das/nas/ (com as) infâncias, para que possamos apreciar sempre com o olhar, a escuta e a conversa(ação)! 


\footnotetext{
${ }^{1}$ Agradecimento à Coordenação de Aperfeiçoamento de Pessoal de Ensino Superior (CAPES) pelo financiamento da pesquisa que originou o artigo

${ }^{2}$ Pensar o pensamento como princípio epistemológico do dever e do cuidado na educação
}

\section{Referências}

BAZÍLIO, Luiz Cavalieri; KRAMER, Sonia. Infância, educação e direitos humanos. 4. ed. São Paulo: Cortez, 2011.

BARCELOS, Valdo; MADERS, Sandra. Humberto Maturana e a Educação: educar no amor

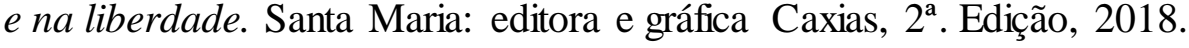

BRANDÃO, Carlos Rodrigues. O que é educação. 43. ed. São Paulo: Brasiliense, 2003.

CAPRA, Fritjof. A teia da vida: uma nova compreensão científica dos sistemas vivos. Tradução Newton Roberval Eichemberg. Editora Cultrix, São Paulo, 2006.

CAPRA, Frigot; LUISI, Pier Luigi. A visão sistêmica da vida: uma concepção unificada e suas implicações filosóficas, políticas, sociais e econômicas/ Frigot Capra, Pier Luigi Luisi; tradução Mayra Teruya Eichemberg, Newton Roberval Eichemberg. - São Paulo: Cultrix, 2014.

CARVALHO, Ana; PEDROSA, Maria Isabel; ROSSETTI-FERREIRA, Maria Clotilde. Aprendendo com a criança de zero a seis anos. São Paulo, Cortez Editora, 2012.

COHN, Clarice. Antropologia da criança. Rio de Janeiro: Jorge Zahar Editor, 2009.

COHN, Clarice. Concepções de infância e infâncias. Civitas. Porto Alegre. V.13. n.2, p.221244, mai-ago, 2013. Disponível em:

http://revistaseletronicas.pucrs.br/ojs/index.php/civitas/article/viewFile/15478/10826. Acesso: 15 jan. 2019.

CORSARO, William Arnould. Sociologia da Infância/ Willian A. Corsaro; tradução Lia Gabrielle Regius Reis; revisão técnica: Maria Leticia B. P. Nascimento. - Porto Alegre, 2011.

DELGADO, Ana Cristina Coll. Estudos socioantropológicos da infância no Brasil. In: FILHO, Altino José Martins; PRADO, Patrícia Dias (Orgs.). Das pesquisas com a complexidade da infância.Campinas: Autores Associados, 2011.

DELGADO, Ana Cristina Coll. Culturas infantis e dimensões da socialização no cotidiano de uma creche domiciliar. Cadernos de Educação. Faculdade de Educação, Pelotas, v. 12, n 21, 2003. Disponível em: https://periodicos.ufpeledu.br/ojs2/index.php/caduc/. Acesso: 08 abr. 2019.

FILHO, Altino José Martins; CASTRO, Joselma Salazar. Avaliação na e da Educação Infantil. Avaliação de Contexto. Pro.posições. v. 29, n.2 (87) mai/ago. 2018. Disponível em: http://dx.doi.org/10.1590/1980-6248-2016-0155. Acesso: 11 fev. 2019. 
GOMES, Marineide de Oliveira. Formação de professores na educação infantil/ Marineide de Oliveira Gomes. -2. Ed. - São Paulo: Cortez, 2013.

GOMÉZ, Guilhermo Orozco. Educomunicação: recepção midiática, aprendizagens e cidadania. Editora: Paulinas, 2017.

MATURANA, Romesín Humberto. Emoções e linguagem na educação e na política. Humberto Maturana; tradução José Fernando Campos Fortes. Belo Horizonte: Ed. UFMG, 1998.

MATURANA, Romesín Humberto; YÁÑEZ, Ximena Dávila. Habitar humano em seis ensaios de biologia cultural. Tradução de Edson Araújo Cabral. -São Paulo, Palas Athena, 2009.

MATURANA, Romesín Humberto; VARELA, Javier Francisco. A árvore do conhecimento: as bases biológicas da compreensão humana. Tradução: Humberto Mariotti e Lia Diskin; ilustração: Carolina Vial, Eduardo Osorio, Francisco Olivares e Marcelo Maturana Montañez. -São Paulo, Palas Athena, 9ª . Edição, 2011.

MATURANA, Romesín Humberto; VERDEN-ZÖLLER, Gerda. Amar e brincar: fundamentos esquecidos do humano do patriarcado à democracia. Tradução de Humberto Mariotti e Lia Diskin. -São Paulo, Palas Athena, 3 ${ }^{\text {a }}$ Edição, 2011.

OLIVEIRA-FORMOSINHO, Júlia (coord.). Modelos curriculares para a educação de infância. Porto: Porto Editora, 1998(b).

PINTO, Manuel; SARMENTO, Manuel. A infância como construção social. In: PINTO, Manuel; SARMENTO, Manuel Jacinto. (coord). As crianças: contextos e identidades. Braga: Centro de Estudos da Criança, Universidade do Minho, 1997.

PISKE, Eliane Lima; BERSCH, Angela Adriane; SILVA, Marcia Soares; JULIANO, Andreia Costa; GARCIA, Narjara Mendes. Educação Ambiental com Crianças: discussões mobilizadas na disciplina te: infância, globalização e participação do grupo social das crianças. In VIII EDEA, 8, 2016, Rio Grande. Anais... Rio Grande: FURG, 2016, p. 572- 579. Disponível em: https $/ /$ drive.google.com/file/d/0B6rmD_1H4no0OW9xUkYzM3FwSENyRTdvaWtLS zk xdE JOajNv/view?ts=5ab3b4b7. Acesso: 24 fev. 2019.

PISKE, Eliane Lima; YUNES, Maria Angela Mattar; GARCIA, Narjara Mendes. Ambientes educativos como contextos microssistêmicos para o desenvolvimento humano na infância. Educação e Saúde- Dossiê do Meio Ambiente. Revista Eletrônica ItinerariusReflexionis. V 15, N. 1, 2019. ISSN 1807-9342, 2019. Disponível em:

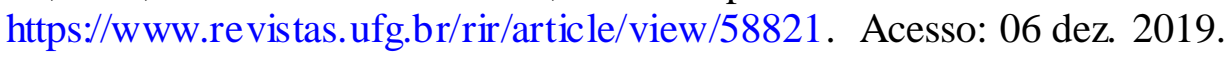

PISKE, Eliane Lima; GARCIA, Narjara Mendes; YUNES, Maria Angela Mattar. Conversa(ação) sistêmica na/para/com a Educação Ambiental das Infâncias. Bio-Grafía. Escritos sobre la Biología y su Enseñanza. Edición Extraordinaria, p. 895-905, 2019. 
Disponível em: https $/ /$ revistas.pedagogica.edu.co/index.php/bio-grafia/index. Acessado em: 10 abr. 2020.

SARMENTO, Manoel Jacinto. Imaginário e culturas da infância. Cadernos de Educação, Pelotas, v. 12, n. 21, 2003. Disponível em:

https $/ /$ periodicos.ufpel.edu.br/ojs2/index.php/caduc/issue/view/141. Acesso: 15 fev. 2019.

STONE, Michael; ZENOBIA, Barlow; ORR, David; CAPRA, Fritjof; duailibi, Mirian. Alfabetização Ecológica: a educação das crianças para um mundo sustentável. - São Paulo: Cultrix, 2006.

VECA, Alberto; SARTI, Alessandro; BRANZI, Andrea; ETRILLO, Antonio; RINALDI, Carla; BRUNER, Jerome; SUSANI, Marco; ICARO, Paolo; VECCHI, Vea. Crianças, espaços e relações: como projetar ambientes para a educação infantil. CEPPI, Giulio., ZINI, Michele (org.). - Porto Alegre: Penso, 2013.

VIANA, Daniela Cristina; PILlOTTO, Silvia Sell Duarte; CARGNIN, Karinna Alves; STRAPAZZON, Miries Antunes Locatelli. Atravessamentos dançantes na infância: experiências corporais, sonoras e visuais. - 1. ed. - Curitiba: Appris, 2017. 